\title{
PENGEMBANGAN BUNDLE DALAM MENURUNKAN URINARY TRACT INFECTION (UTI) DI RSUD SEJIRAN SETASON MUNTOK
}

\section{THE DEVELOPMENT BUNDLE TO DECREASE URINARY TRACT INFECTION (UTI) IN SEJIRAN SETASON MUNTOK HOSPITAL}

\author{
Ani Syafriati ${ }^{1 *}$, Elsye Maria Rosa ${ }^{2}$, Novita Kurnia Sari ${ }^{3}$ \\ *1Universitas Muhammadiyah Yogyakarta Program Pascasarjana, Jalan Brawijaya, Kasihan, Tamantirto, \\ Kasihan, Bantul, Daerah Istimewah Yogyakarta, syafriatiani92@gmail.com, Indonesia \\ 2Universitas Muhammadiyah Yogyakarta Program Pascasarjana, Jalan Brawijaya, Kasihan, Tamantirto, \\ Kasihan, Bantul, Daerah Istimewah Yogyakarta, Indonesia \\ ${ }^{3}$ Universitas Muhammadiyah Yogyakarta Program Pascasarjana, Jalan Brawijaya, Kasihan, Tamantirto, \\ Kasihan, Bantul, Daerah Istimewah Yogyakarta, Indonesia
}

\begin{abstract}
Background: Development of CAUTI bundle is very important to evaluate the nurse in implementing nursing practice related to urinary catheter which is one of prevention efforts and risk control of CAUTI.

Objective: The purpose of this study is to develop CAUTI bundle that is adjusted to hospital condition in Sejiran Setason Muntok Hospital.

Methods: In this study used qualitative method by conducting indepth interview and focus group discussion (FGD). It conducted for 3 weeks in Sejiran Setason Muntok Hospital, the total sample are 22 participants. The result produced the themes that used as the material for the development of the bundle or the observation sheet of CAUTI.

Results: There are 10 themes which become material for the development of CAUTI bundle. The CAUTI Bundle consists of bundle components such as indication of urinary catheter insertion, urinary catheter installation must comply with SOP, monitoring of urine output by regularly, emptying urine bag regularly, performing hand hygiene before and after procedure, using masks and handscoons, patients and families must be aware of their role in minimizing the risk of CAUTI.
\end{abstract}

Conclusion: Development of the bundle is very important as one of prevention of CAUTI incident in hospital.

Keyword : Bundle, CAUTI, Development.

\section{PENDAHULUAN}

Catheter Associated Urinary Tract Infection (CAUTI) merupakan salah satu kejadian infeksi yang sangat sering terjadi di rumah sakit. CAUTI adalah istilah yang dipakai untuk menyatakan adanya invasi mikroorganisme pada saluran kemih atau ditemukan bakteri didalam urine. CAUTI dapat terjadi disaluran ginjal (ureter), kandung kemih (bladder) atau saluran kencing bagian luar uretra. $^{1}$ Menurut hasil survei Centers for Disease Control Prevention (CDC), pada tahun 2011 didapatkan hasil catheter associated urinary tract infection (CAUTI) sebanyak 93.300 kasus. $^{2}$ Sementara itu kejadian CAUTI di Indonesia masih tinggi yaitu sebesar $114,75 \%{ }^{3}$ Data kejadian CAUTI di RSUD Semarang tahun 2009 sebanyak 23 kejadian. ${ }^{4}$ Di RSU Haji Surabaya tahun 2014 terdapat 15 kejadian CAUTI. ${ }^{5}$ Di RSU DR. Mohammad Hoesin Palembang kejadian CAUTI sebesar 20,84\%. ${ }^{3}$

Dengan semakin meningkatnya kejadian CAUTI di rumah sakit, maka perlu dilakukannya evaluasi pencegahan dan 
pengendalian CAUTI dengan melibatkan semua petugas rumah sakit, terutama peran perawat menjadi hal pertama untuk mencegah terjadinya CAUTI. $^{6}$ Dalam mengendalikan Catheter Associated Urinary Tract Infection (CAUTI) di rumah sakit perlu adanya sistem surveilan yang baik yakni melakukan tindakan pengamatan yang sistemik dan dilakukan terus menerus terhadap penyakit yang terjadi pada populasi dengan tujuan dapat melakukan pencegahan dan pengendalian. Keberhasilan pengendalian kejadian CAUTI bukanlah ditentukan oleh canggihnya peralatan yang ada, tetapi ditentukan oleh kesempurnaan perilaku petugas dalam memberikan perawatan penderita secara baik dan benar. Didalam pelaksanaan surveilan ini, perawat merupakan petugas lapangan digaris terdepan memiliki peran yang sangat menentukan. ${ }^{1}$

Pengembangan bundle CAUTI ini sangat penting untuk mengevaluasi perawat dalam melaksanakan praktik keperawatan yang berhubungan dengan pemasangan kateter urine yang merupakan salah satu upaya pencegahan serta pengendalian resiko kejadian CAUTI. Dengan adanya pengembangan bundle ini dapat meningkatkan peran perawat dalam membuat strategi pencegahan dan pengendalian di ruang perawatan, hal ini juga dirasa sangat perlu dengan menimbang resiko kejadian CAUTI yang apabila tidak ada pengembangan bundle ini, maka angka kejadian CAUTI akan semakin meningkat.

\section{BAHAN DAN CARA PENELITIAN}

Dalam penelitian ini menggunakan metode kualitatif dengan melakukan indepth interview (wawancara mendalam) dan focus group discussion (FGD). Dilakukan selama 3 minggu di RSUD Sejiran Setason Muntok dengan total sampel sebanyak 22 partisipan, yaitu dengan melakukan wawancara mendalam terhadap 6 perawat, 6 kepala ruangan, kasie keperawatan, IPCN, dokter bedah dan dokter penyakit dalam tentang Catheter Associated Urinary Tract Infection (CAUTI) dan melakukan focus group discussion (FGD) pada setiap 6 IPCLN ruangan. Kemudian menganalisa data tersebut dengan mentranskrip data, menentukan meaning unit, melakukan abstraksi data (koding, kategori, menyusun tema), yang kemudian menghasilkan tematema yang menjadi bahan pembuatan pengembangan bundle atau lembar observasi CAUTI.

\section{HASIL DAN PEMBAHASAN}

Hasil indepth interview dan focus group discussion (FGD) yang dilakukan oleh peneliti dikelompokkan berdasarkan pertanyaan yang diajukan. Indepth interview dan focus group discussion (FGD) dilakukan untuk memperoleh data terkait faktor-faktor perencanaan pembuatan pengembangan Bundle CAUTI RSUD Sejiran Setason 
Muntok. Untuk lebih jelas dapat dilihat pada gambar 1 dibawah ini.

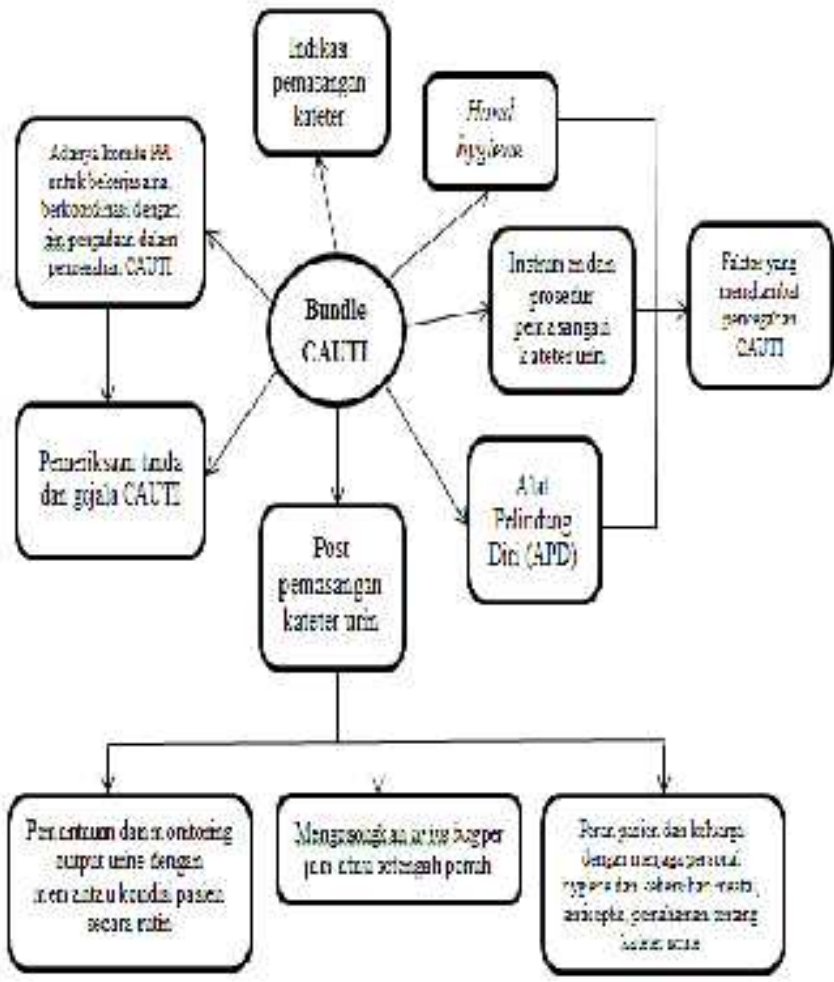

Gambar 1. Skema hasil tema-tema. ${ }^{7}$

Didapatkan 10 tema sebagai bahan dasar pengembangan Bundle CAUTI, yakni sebagai berikut :

1. Indikasi pemasangan kateter urine Indikasi pemasangan kateter merupakan pendapat yang diungkapkan oleh perawat sesuai pemahaman mereka indikasi pasien yang diharuskan menggunakan kateter urine yang meliputi keterbatasan mobilitas, penurunan kesadaran, pre-post operasi, kecelakaan, cek output dan input cairan, pasien dengan penyakit jantung dan stroke.

2. Instrumen dan prosedur pemasangan

Berdasarkan informasi dari partisipan tentang Instrumen dan prosedur pemasangan kateter urin dilakukan dengan informed consent, ukuran kateter sesuai kebutuhan, tehnik aseptic, disinfektan area penis, vulva hygiene, prosedur sesuai SOP dan prinsip steril.

3. Pemantauan dan monitoring output urine Berdasarkan hasil wawancara dengan partisipan didapatkan informasi tentang pemantauan dan monitoring output urine antara lain pantau berapa hari sekali, memperhatikan kondisi pasiennya, memantau untuk pasien-pasien yang terpasang kateter, secara rutin kateter dilihat pelepasan atau penggantian.

4. Pemeriksaan tanda dan gejala CAUTI

Berdasarkan hasil wawancara dengan partisipan didapatkan informasi tentang pemeriksaan tanda dan gejala CAUTI antara lain pasien mengeluh nyeri, demam, atau disekitar daerah yang dipasang kateter itu ada luka lecet, infeksi.

5. Mengosongkan urine bag per jam atau setengah penuh

Berdasarkan hasil wawancara dengan partisipan didapatkan informasi tentang mengosongkan urine bag per jam, kantong setengah penuh, libatkan keluarga cara pembuangan urine, observasi jumlah urine pasien.

\section{Hand hygiene}

Berdasarkan wawancara dengan partisipan didapatkan informasi tentang hand hygiene dilakukan dengan kewaspadaan standar antara lain cuci tangan 6 langkah, menggunakan handrub, handsoap dan 
lakukan sosialisasi cuci tangan pegawai dan pengunjung RS.

7. Alat pelindung diri (APD) untuk pemasangan kateter urine

Berdasarkan hasil wawancara dengan partisipan didapatkan informasi tentang alat pelindung diri (APD) anatar lain menggunakan handscoon steril, masker, celemek.

8. Peran pasien dan keluarga

Berdasarkan hasil wawancara dengan perawat didapatkan informasi tentang peran pasien dan keluarga antara lain edukasi tentang kateter urine, personal hygiene kebersihan meatal, penjelasan fungsi dan tujuan penggunan kateter urine, kerjasama dengan keluarga pasien, dan antiseptic bagi keluarga yang besuk.

9. Faktor yang menghambat pencegahan CAUTI

Berdasarkan wawancara dengan partisipan didapatkan informasi tentang faktor yang menghambat pencegahan CAUTI antara lain sarana dan prasarana yang belum memadai, belum ada pelatihan, edukasi atau sosialisasi ke perawat, pembaharuan ilmu, alat instrument pemasangan kateter urine (ukuran kateter, set kateter, duk bolong), kepatuhan perawat, sumber daya manusia, kesadaran perawat penggunaan prinsip steril, terkendala untuk permintaan alat pengadaan ke manajemen, PPI sempat vakum hampir 7 bulan, keterlambatan pengumpulan laporan oleh tim IPCLN ke PPI.

\section{Adanya Komite PPI}

Berdasarkan informasi dari partisipan tentang adanya komite PPI yakni mulai 2018 ini ada komite PPI, pencatatan dan pencegahan CAUTI dan bekerjasama, berkoordinasi dengan tim pengadaan untuk mengingatkan.

Berdasarkan hasil dari tema-tema tersebut kemudian dituangkan menjadi komponen-komponen untuk pembuatan bundle. Bundle CAUTI ini bertujuan untuk mengurangi kejadian CAUTI dalam masa perawatan dan memeriksa perawatan kateter secara detail.

Tabel 1

Bundle perawatan CAUTI (Catheter Associated Urinary Tract Infection) di RSUD Sejiran Setason Muntok. Komponen Bundle Kriteria pemenuhan untuk Bundle
Indikasi pemasangan kateter urine.
1. Pemasangan kateter urin harus sesuai indikasi. Apabila pasien sudah tidak membutuhkan kateter urine harus segera dilepas.

2. Apabila tidak terdapat indikasi klinis kateter harus dilepas.

\begin{tabular}{|c|c|}
\hline $\begin{array}{l}\text { Pemasangan } \\
\text { kateter urine harus } \\
\text { sesuai SOP, mulai } \\
\text { dari instrument dan } \\
\text { prosedur } \\
\text { pemasangan. }\end{array}$ & $\begin{array}{l}\text { 1. Ukuran selang } \\
\text { kateter urine harus } \\
\text { sesuai dengan } \\
\text { kebutuhan pasien. } \\
\text { 2. Mengunnakan } \\
\text { prinsip steril. }\end{array}$ \\
\hline $\begin{array}{lr}\text { Pemantauan } & \text { dan } \\
\text { monitoring } & \text { output } \\
\text { urine } & \text { dengan } \\
\text { memantau } & \text { kondisi } \\
\text { pasien secara rutin. }\end{array}$ & $\begin{array}{l}\text { 1. Memantau pasien } \\
\text { yang } \\
\text { menggunakan } \\
\text { kateter urine } \\
\text { dengan waktu yang } \\
\text { lama. } \\
\text { 2. Memastikan tidak } \\
\text { ada nyeri di area }\end{array}$ \\
\hline
\end{tabular}


pemasangan

kateter

(suprapubik, skrotum, dll).

3. Memastikan kateter dan urine bag tidak bocor.

4. Memeriksa area kulit pasien apakah terdapat iritasi, kemerahan, atau dekubitus.
Mengosongkan urine bag secara teratur dengan wadah yang bersih. Apabila mengambil urine sebagai sampel untuk laboratorium harus memastikan urine bag dalam keadaan tertutup kembali.
1. Urine bag harus dikosongkan secara teratur, sebagai prosedur terpisah, ke dalam wadah bersih.

2. Mengosongkan urine bag per jam atau setengah penuh, libatkan keluarga dan observasi jumlah urine.

3. Memastikan urine bag tertutup kembali (terkunci) setelah mengambil urine atau mengosongkan urine. Hand hygiene dilakukan dengan kewaspadaan standar antara lain cuci tangan 6 langkah, menggunakan handrub, handsoap dan lakukan sosialisasi cuci tangan pegawai dan pengunjung RS.

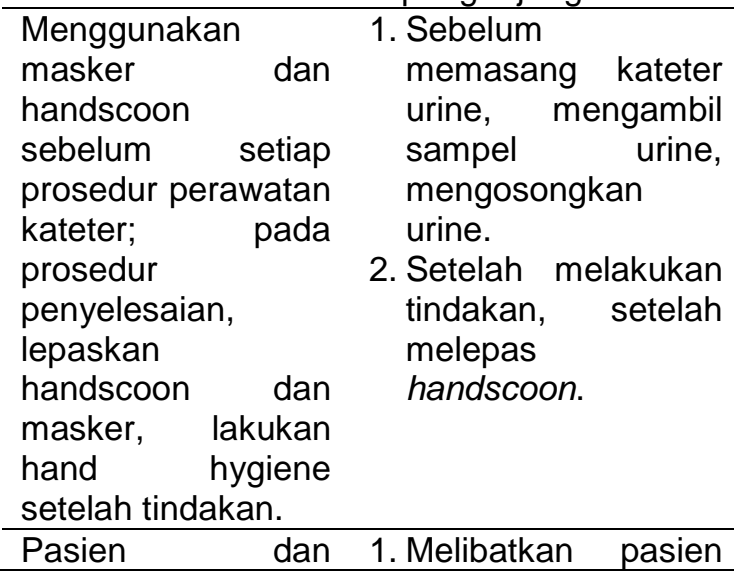

\begin{tabular}{lr}
\hline Melakukan & hand \\
hygiene sebelum & setelah \\
dan & sasedur perawatan \\
prose \\
kateter.
\end{tabular}

keluarga menyadari meminimalkan risiko terkena infeksi saluran kemih atau memastikan kebersihan meatal rutin setiap hari dilakukan. perannya dalam dan keluarga dalam perawatan kateter urine dengan memberikan edukasi cara perawatan kateter dan meminimalkan komplikasi CAUTI.

2. Melakukan kebersihan meatal secara rutin

\section{PEMBAHASAN}

Indikasi pemasangan kateter urin merupakan syarat penting dalam pencegahan kejadian CAUTI. Kateter urin digunakan apabila pasien benar-benar membutuhkan, apabila pasien mampu untuk melakukan eliminasi atau buang air kecil secara mandiri atau melalui bantuan pispot, sebaiknya tidak dipasang kateter urine. Hal ini menjadi acuan untuk mengurangi pemakaian kateter yang tidak perlu dan mencegah terjadinya infeksi akibat kateter. Apabila menggunakan kateter terlalu sering, lama dan tidak sesuai indikasi akan meningkatkan resiko berbagai komplikasi. ${ }^{8}$

Dalam prosedur pemasangan kateter urin perlunya memperhatikan beberapa aspek penting seperti instrument yang digunakan, pelaksanaan dengan prinsip steril, tehnik aseptik dan dilakukan sesuai standar operasional prosedur (SOP) yang berlaku di rumah sakit. Pada instrument penting untuk memperhatikan ukuran selang kateter yang sesuai dengan kebutuhan pasien agar tidak terjadi kebocoran atau membuat iritasi pada pasien. Penggunaan alat pelindung diri seperti masker, handscoon bersih dan steril, serta celemek sangat 
penting dalam pencegahan kejadian CAUTI. Selain itu juga dengan menerapkan kewaspadaan standar seperti hand hygiene. ${ }^{9}$

Pasien yang terpasang kateter urin harus terus dipantau setiap hari. Tidak hanya pasien yang harus diobservasi output dan input cairannya, setiap pasien yang menggunakan kateter urine harus dipantau. Dalam hal ini pemantauan yang dimaksudkan adalah perawat mengecek kantong drainase urin atau urine bag pasien apakah terdapat hematuria, mengecek kualitas aliran selang kateter apakah terdapat kebocoran, dan memantau keadaan pasien apakah terdapat tanda dan gejala CAUTI seperti demam, nyeri pada area selang kateter, iritasi atau kemerahan pada area kulit. ${ }^{10,11}$

Pasien yang menggunakan kateter urin sangat beresiko untuk terjadinya CAUTI. Perawat memiliki peran penting dalam memantau dan mencegah terjadinya kejadian CAUTI. Tanda dan gejala CAUTI yang sering ditemui adalah adanya nyeri di area suprapubik, pasien mengalami demam tinggi, terdapat luka lecet, kemerahan atau iritasi pada area kulit disekitar selang kateter. ${ }^{11}$

Urine harus dibuang secara teratur, hal ini merupakan salah satu langkah pencegahan CAUTI. Urine harus dibuang dalam wadah yang bersih. Mengevaluasi efektifitas dari strategi intervensi bundel pada tingkat CAUTI secara keseluruhan, yaitu kebersihan tangan dengan tepat, mempertahankan urine bag lebih rendah dari tingkat kandung kemih, mempertahankan aliran urin agar tidak terhalang, mengosongkan urine bag secara reguler dan menghindari penutup urine bag menyentuh wadah penampung, dan memantau CAUTI menggunakan kriteria standar., 9,12

Hand hygiene atau cuci tangan merupakan salah satu langkah dasar dalam pencegahan kejadian CAUTI. Hand hygiene dapat dilakukan dengan cara handwash menggunakan sabun atau menggunakan handrub atau cairan antiseptik lainnya. Alat pelindung diri (APD) merupakan pencegahan utama dalam pemasangan kateter urin. Pada pemasangan kateter urin, alat pelindung diri yang biasa digunakan antara lain handscoon bersih, handscoon steril, masker dan celemek. ${ }^{9,10}$

Selama pasien terpasang kateter urin, perawat juga harus melibatkan keluarga dalam menjaga kateter urin. Perawat harus memberikan edukasi tentang pemasangan kateter urin, mulai dari tujuan dan fungsi kateter urin, efek yang akan diterima pasien, menjaga kebersihan meatal pasien, peletakan urine bag yang lebih rendah dan sebagainya. Dengan melibatkan peran pasien dan keluarga diharapkan mampu memberikan pemahaman untuk tetap menjaga kebersihan personal hygiene pasien dan mencegah terjadinya CAUTI. ${ }^{13}$

Faktor-faktor yang dapat mempengaruhi kejadian CAUTI adalah sarana dan prasarana rumah sakit yang belum memadai, alat dan instrument untuk memasang kateter urin, kesadaran perawat 
dan peran PPI dalam mencegah CAUTI itu sendiri. ${ }^{14}$ Komite Pengendalian dan Pencegahan Infeksi (PPI) merupakan kegiatan surveilans, untuk mencatat dan melaporkan kejadian CAUTI. Selain itu PPI juga melakukan kegiatan seperti pendidikan dan pelatihan, kewaspadaan isolasi yang termasuk dalam program pengendalian infeksi dan harus dilakukan untuk mencapai keberhasilan setiap program PPI. Faktorfaktor ini membuat pelayanan kesehatan menjadi sangat tidak maksimal dan akan membuat citra rumah sakit menjadi buruk. ${ }^{2,15}$

\section{KESIMPULAN}

Dalam penelitian ini didapatkan 10 tema yang menjadi bahan pengembangan bundle CAUTI, yang kemudian diringkas menjadi komponen-komponen bundle antara lain indikasi pemasangan kateter urin, pemasangan kateter urine harus sesuai SOP mulai dari instrument dan prosedur pemasangan, pemantauan dan monitoring output urine dengan memantau kondisi pasien secara rutin, mengosongkan urine bag secara teratur dengan wadah yang bersih. Apabila mengambil urine sebagai sampel untuk laboratorium harus memastikan urine bag dalam keadaan tertutup kembali. Melakukan hand hygiene sebelum dan setelah prosedur. Menggunakan masker dan handscoon sebelum setiap prosedur perawatan kateter; pada prosedur penyelesaian, lepaskan handscoon dan masker, lakukan hand hygiene setelah tindakan. Pasien dan keluarga menyadari perannya dalam meminimalkan risiko terkena infeksi saluran kemih atau memastikan kebersihan meatal rutin setiap hari dilakukan.

Saran yang dapat peneliti berikan antara lain menerapkan bundle CAUTI ke seluruh ruangan pelayanan kesehatan di rumah sakit, mengembangkan dan menambah refrensi setiap komponen pada Bundle CAUTI disesuaikan dengan sarana prasarana rumah sakit tersebut, mengadakan edukasi (pembaharuan ilmu) atau pelatihan tentang pemasangan kateter dan pencegahan kejadian CAUTI untuk seluruh perawat di ruang rawat inap, meningkatkan sarana dan prasarana rumah sakit, seperti penyediaan alat instrument pemasangan kateter, melengkapi fasilitas handrub, handsoap di setiap ruangan, meningkatkan keaktifan PPI dalam kegiatan monitoring ke ruang rawat inap untuk memantau adanya kejadian CAUTI, memberikan pelatihan khusus pencegahan dan pengendalian CAUTI untuk IPCN dan IPCLN setiap ruangan.

\section{TERIMA KASIH}

1. Bapak Yudi Widyansa, SKM., MM, selaku Direktur RSUD Sejiran Setason Muntok. Email : rsud.sejiransetason@ymail.com.

2. Ibu Linda Anggeriani ST. selaku IPCN RSUD Sejiran Setason Muntok. Email: lindaarsul@gmail.com

3. Ibu Dedeh Setia Ningsih, S.Kep., Ns, selaku Kasie Keperawatan RSUD Sejiran 
Setason Muntok. Email:

rsud.sejiransetason@ymail.com.

\section{KEPUSTAKAAN}

1. Septiari, B.B. Infeksi Nosokomial. Yogyakarta : Nuha Medika; 2012.

2. Magill S.S, Edwards J.R, \& Bamberg W. Multistate Point-Prevalence Survey of Health Care-Associated Infections. The New England Journal of Medicine. From the Centers for Disease Control and Prevention 2014; Volume 370, Nomor 13.

3. Rosa E.M. Surveilence Incidences Hais : Urinary Tract Infection (UTI), Surgical Site Infection (SSI), And Phlebitisat Hospitalin Indonesia. International Journal of Recent Advances in Multidisciplinary Research 2017; Volume 04, Nomor 01, halaman 2147-2150.

4. Aisyah, Z \& Satyabakti, P. Surveilans Infeksi Daerah Operasi (IDO) menurut Komponen Surveilans di Rumah Sakit X Surabaya tahun 2012. Departemen Epidemiologi Fakulatas Kesehatan Masyarakat Universitas Airlangga, Surabaya Jawa Timur. Jurnal berkala epidemilogi, Volume 1, nomor 2 September 2013, halaman 254-265.

5. Vebrilian, S.R. Surveilans catheter associated urinary tract infection berdasarkan atribut surveilans di RSU Haji Surabaya. Departemen Epidemiologi Fakultas Kesehatan Masyarakat Universitas Airlangga. Jurnal Berkala Epidemiologi, Volume 4 Nomor 3, September 2016, hlm. 313-325.

6. The Joint Commission. Requirements for the Catheter-Associated Urinary Tract Infections (CAUTI) National Patient Safety Goal for Hospitals. Standard NPSG.07.06.01. 2017.

7. Centers for Disease Control prevention (CDC). Urinary Tract Infection (CatheterAssociated Urinary Tract Infection [CAUTI] and Non-Catheter-Associated Urinary Tract Infection [UTI]) and Other Urinary System Infection [USI]) Events; 2017.
8. Nuwa M.S, Arsa S.A.W, Nisa K, et.al. Intervensi Keperawatan Untuk Pencegahan Cauti Pada Pasien Dewasa Yang Tepasang Kateter Indwelling : Literatur Review. Research Gate; 2018.

9. Connor, B.T. Best Practices: CAUTI Prevention. Reducing catheterassociated urinary tract infections. Health Com Media; 2018.

10. Henry, M. Evaluation of evidence-based practice of catheter associated urinary tract infections prevention in a critical care setting: An integrative review. Journal of Nursing Education and Practice. 2018; Volume 8, Nomor 7.

11. Utami A.K \& Sulisno M. Gambaran Pengetahuan Perawat Mengenai Catheter Associated Urinary Tract Infection (CAUTI) Di RSUD H. Soewondo Kendal. Jurnal Departemen IImu Keperawatan. Universitas Diponegoro Semarang; 2017.

12. Galiczewski J.M \& Shurpin K.M. An intervention to improve the catheter associated urinary tractinfection rate in a medical intensive care unit: Direct observation ofcatheter insertion procedure. Intensive and Critical Care Nursing. Elsevier; 2017.

13. Sumolang S.A.CH., Porotu'o J \& Soeliongan S. Pola Bakteri Pada Penderita Infeksi Saluran Kemih Di BLU RSUP Prof. Dr. R. D. Kandou Manado. Jurnal e-Biomedik (eBM), 2016; Volume 1, Nomor 1, hlm. 597-601.

14. Sarani $H$, Balouchi $A$, \& Masinaeinezhad N. Knowledge, Attitude and Practice of Nurses about Standard Precautions for Hospital-Acquired Infection in Teaching Hospitals Affiliated to Zabol University of Medical Sciences. Global Journal of Health Science. 2016; Volume 8, Nomor 3.

15. Saint S, Greene T, \& Krein S.L. A Program to Prevent Catheter-Associated Urinary Tract Infection in Acute Care. The New England Journal of Medicine 2016; volume 374 , Nomor 22, halaman 2111-9. 